\title{
O Programa Justiça Restaurativa para o Século 21 do Tribunal de Justiça do Estado do Rio Grande do Sul: Relatos da experiência do processo de institucionalização da Justiça Restaurativa no Poder Judiciário do RS
}

\section{El Programa de Justicia Restaurativa para el siglo XXI de la Corte de Justicia del Estado de Rio Grande do Sul: Informes de la experiencia del proceso de institucionalización de la Justicia Restaurativa en el Poder Judicial de RS}

\author{
Ana Paula Pereira Flores ${ }^{1}$
}

\begin{abstract}
Resumo: O percurso da institucionalização da Justiça Restaurativa no Poder Judiciário do Estado do Rio Grande Sul iniciou-se por meio da adoção das práticas restaurativas na Central de Práticas Restaurativas (CPR) do Juizado da Infância e Juventude de Porto Alegre, instituída por meio da Resolução do Conselho da Magistratura (Comag/TJRS) no 822, de 05 de fevereiro de 2010, quando ainda o tema da justiça restaurativa encontrava-se em embrionária discussão, tanto no Estado do Rio Grande do Sul quanto no Brasil. Em 21 de outubro de 2014, o Poder Judiciário do RS, por iniciativa de sua Corregedoria-Geral de Justiça (CGJ), instituiu o Programa Justiça Restaurativa para o Século 21, "com o propósito de difundir, de implantar, de aprimorar e de consolidar a Justiça Restaurativa no Primeiro Grau da Justiça Estadual". É deste processo de institucionalização que este artigo estará discorrendo, como o relato de uma experiência inicial de incorporação das práticas e princípios restaurativos no cotidiano da feitura judicial no Poder Judiciário gaúcho.
\end{abstract}

Palavras-chave: Justiça restaurativa, Institucionalização, Política judiciária, Relato de experiencia, Tribunal de justiça do Estado do Rio Grande do Sul .

\begin{abstract}
El curso de la institucionalización de la justicia restaurativa en el poder judicial del estado de Rio Grande Sul comenzó mediante la adopción de prácticas restaurativas en las prácticas restauradoras centrales (CPR) de la corte juvenil y juvenil de Porto Alegre, InStituido a través de la resolución del Consejo de la magistratura (CoMag/TJRS) no 822, de 05 de febrero de 2010, cuando el tema de la justicia restaurativa se encontraba en discusión embrionaria, tanto en el estado de Rio Grande do Sul como en Brasil. El 21 de octubre de 2014, el poder judicial de la $R S$, por iniciativa de sus asuntos internos-justicia general (CGJ), instituyó el programa de justicia restaurativa para el siglo XXI, "con el propósito de difundir, implementar, mejorar y consolidar la justicia restaurativa En el primer grado de Justicia del estado". Es a partir de este proceso de institucionalización que este artículo se desintegrará, como el informe de una experiencia
\end{abstract}

\footnotetext{
${ }^{1}$ Advogada. Mestra em Serviço Social pelo Programa de Pós-Graduação em Serviço Social da Escola de Humanidades da Pontifícia Universidade Católica do Rio Grande do Sul (PUCRS). Assessora do Programa Justiça para o Século 21, do Tribunal de Justiça do Estado do Rio Grande do Sul de Abril de 2015 até Agosto de 2018.
} 
inicial de incorporar las prácticas y principios restaurativos en la rutina diaria de procedimiento judicial en el poder judicial gaucho.

Keywords: Justicia restaurativa, Institucionalización, Política judicial, Informe de experiencia, Tribunal de Justicia del Estado de Rio Grande do Sul.

\section{Introdução}

A justiça restaurativa está fundamentada em uma perspectiva de fortalecimento da horizontalidade nos processos decisórios, para que possam acontecer de forma dialogada e de iniciativa dos(as) próprios(as) participantes das demandas judicias, mas, também, anteriormente à judicialização destas. Dentro deste contexto, prioriza e potencializa a criatividade e a sensibilização dos(as) protagonistas das contendas, por meio de uma escuta mais apurada das vítimas e de se seus respectivos(as) ofensores(as), viabilizando, assim, a aproximação desses, de forma conjunta às suas famílias e suas comunidades. Segundo Marshall (1999), a Justiça Restaurativa define-se como sendo "um processo onde todas as partes ligadas de alguma forma a uma particular ofensa, vêm discutir e resolver coletivamente as consequências práticas da mesma e as suas implicações no futuro". Na visão de Zehr (2008), a justiça restaurativa pode ser pensada como "um novo foco sobre a justiça e os crimes", sendo que, essa proposta de uma nova concepção para a justiça fundamenta-se em princípios cunhados a partir de críticas ao sistema de justiça tradicional, e sob uma perspectiva internacional de buscar alternativas para o fomento de uma nova visão, sobre e para os sistemas de justiça no mundo. Embora, se mostrando particularmente propícia para tal fim, a justiça restaurativa não se resume a uma modalidade de resolução de conflitos, alternativa ou mais adequada, nem suas aplicações se esgotam no campo das infrações penais. Pode-se afirmar, assim, que não será possível vislumbrar a implementação da justiça restaurativa como uma alternativa comunitária, ou como uma política pública nacional judiciária mais adequada de resolução de conflitos, sem pensar no enfrentamento e desvendamento das inúmeras expressões da questão social que envolve a situação atual do Brasil.

Nesse contexto, os marcos normativos internacionais e nacionais sobre justiça restaurativa passaram a traçar um novo delinear para essa proposta de redirecionamento da justiça no mundo e no Brasil. Em âmbito internacional, a regulamentação da justiça restaurativa teve início pelos atos do Conselho Econômico e Social (CES) das Organiza- 
ções das Nações Unidas (ONU):

a) Resolução CES/ONU no 1.999/26, de 28 de julho de 1999: que dispõe sobre a "Elaboração e aplicação de medidas de mediação e justiça restaurativa em matéria de justiça criminal";

b) Resolução CES/ONU no 2.000/14, de 27 de julho de 2000: intitulada "Princípios básicos sobre a utilização de programas de justiça restaurativa em matéria criminal”;

c) Resolução CES/ONU no 2.002/12, de 24 de julho de 2002: então definiu "Princípios Básicos para a utilização de Programas de Justiça Restaurativa em Matéria Criminal".

Desde então, as propostas de programas de atendimento com metodologias afetas à justiça restaurativa, se propagaram em nível mundial e nacional, já sendo possível acessar diversas publicações teóricas e avaliativas sobre esses trabalhos. Mas, mesmo sendo ainda singela a produção teórica nacional, a partir do que se lê, já é possível constatar uma difusão da justiça restaurativa em larga escala, que, com base em seus princípios e estratégias de pacificação social, passam a propor uma ressignificação dos fatos, por parte das vítimas, bem como de possibilidades de expectativas de construção de novos projetos de vida, por aqueles(as) que violam, ou são levados(as) à violação das regras jurídicas e sociais de convivência.

\section{Justiça Restaurativa no Brasil}

Na realidade brasileira, principalmente, a partir da promulgação da Constituição da República Federativa do Brasil (CRFB), em 1988, iniciou-se um processo de redemocratização no país, que ainda está em curso, mas, constantemente ameaçado por sérias rupturas, em função da vigência de distintas visões de projetos de estado, que envolvem os contextos econômicos, culturais, sociais, políticos, e que, interferem na implantação e gestão das políticas públicas, inclusive judiciárias.

Já no preâmbulo de nossa constituição, a solução pacífica de conflitos foi referendada com uma alternativa interna e externa de resolução das controvérsias nacionais. Esse marco constitucional do Estado Democrático de Direito no Brasil, passou a fomentar os seus princípios fundamentais constantes em seu artigo 1ํ: (I) a soberania; (II) a 
cidadania; (III) a dignidade da pessoa humana; (IV) os valores sociais do trabalho e da livre iniciativa; e (V) o pluralismo político.Além disto, o dispositivo referenda também que, todo o poder emana da população. Ainda, previu seus objetivos fundamentais no artigo 2: (I) a construção de uma sociedade livre, justa e solidária; (II) a garantia do desenvolvimento nacional; (III) a erradicação da pobreza e da marginalização e a redução das desigualdades sociais e regionais; (IV) a promoção do bem de todos, sem preconceitos de origem, raça, sexo, cor, idade e quaisquer outras formas de discriminação.

Esses dispositivos iniciais da nossa constituição, passaram a referendar uma visão social de fortalecimento dos direitos de cidadania e da prevalência de uma visão participativa e pacificadora. A carta cidadã, quando passou a tratar dos princípios a serem observados nas suas relações internacionais, ressaltou em seu artigo 4o: (I) a independência nacional; (II) a prevalência dos direitos humanos; (III) autodeterminação dos povos; (IV) não-intervenção; (V) a igualdade entre os Estados; (VI) a defesa da paz (VII) a solução pacífica de conflitos; (VIII) repúdio ao terrorismo e ao racismo; (IX) cooperação entre os povos para o progresso da humanidade; $(X)$ e a concessão de asilo político. Desta forma, a visão dialógica e voltada para a defesa da cidadania ficou plenamente contemplada na carta constitucional.

A justiça restaurativa iniciou sua trajetória no Brasil há pouco mais de 10 anos, quando, entre os anos de 2004 e 2005, o Ministério da Justiça (MJ) por meio de sua Secretaria de Reforma do Judiciário (SRJ), iniciou a implantação do projeto "Promovendo Práticas Restaurativas no Sistema de Justiça Brasileiro", financiado pelo Programa das Nações Unidas para o Desenvolvimento (PNUD). A execução do referido projeto deu espaço ao início da concretização de três projetos-piloto de implantação de práticas restaurativas, quais sejam: 1) São Caetano (SP); 2) Brasília (DF); e 3) Porto Alegre (RS), todos vinculados ao Poder Judiciário. Segundo dados do Instituto Latino-Americano das Nações Unidas para Prevenção do Delito e Tratamento do Delinquente (ILANUD) da ONU, do ano de 2006, em São Caetano (SP) a experiência se vinculou às escolas públicas e privadas, auxiliando na prevenção e não agravamento de conflitos, e foi desenvolvido pela Vara e Promotoria da Infância e Juventude. Na capital federal (DF), o projeto foi executado nos $1^{\circ}$ e $2^{\circ}$ Juizados Especiais de Competência Geral do Núcleo Bandeirante, o qual abrange cinco regiões administrativas do Distrito Federal, e envolveu somente 
conflitos de competência dos Juizados Especiais Criminais (JEC). Em Porto Alegre (RS), a aplicação das práticas restaurativas teve início na 3aㅡ Vara Regional do Juizado da Infância e Juventude, especificamente no âmbito do processo de execução das Medidas Socioeducativas (MSE).

A utilização dos métodos consensuais de resolução de conflitos no âmbito do Poder Judiciário brasileiro foi regulamentado, inicialmente, por meio da Resolução do Conselho Nacional de Justiça (CNJ) no 125, de 29 de novembro de 2010, que dispôs sobre a Política Judiciária Nacional de tratamento adequado de conflitos de interesses no âmbito do Poder Judiciário, que dentre outras importantes definições, criou os Núcleos Permanentes de Métodos Consensuais de Solução de Conflitos (Nupemecs) e os Centros Judiciários de Solução de Conflitos e Cidadania (Cejuscs). Relevante destacar que, essa resolução foi atualizada em dois momentos: 1) Emenda $n^{\circ}$ 01, de 31 de janeiro de 2013, que incluiu alguns tópicos relativos à Justiça Restaurativa dentre outros temas; e, b) Emenda $n^{\circ} 02$, de 08 de março de 2016, que atualizou as regulamentações dessa resolução, de âmbito judiciário, às legislações mais recentes que consolidaram os temas da conciliação e mediação, tais como: a Lei Federal n 13.140, de 26 de junho de 2015 Lei de Mediação, e a Lei Federal n 13.105, de 16 de março de 2015 - Novo Código de Processo Civil.

Ainda, em 31 de maio de 2016, o CNJ editou a Resolução no 225, que dispõe sobre a Política Nacional de Justiça Restaurativa, no âmbito do Poder Judiciário brasileiro, legitimando as técnicas e metodologias como partes integrantes do rol dos métodos autocompositivos de resolução de conflitos judiciais. A resolução em questão acabou por definir um conceito para a justiça restaurativa; indicar alguns parâmetros para a estruturação básica dos atendimentos dos conflitos; e, ainda, definir algumas categorias importantes na seara da ambientação restaurativa, tais como: prática restaurativa, procedimento restaurativo, caso, sessão restaurativa, enfoque restaurativo. Essa normativa definiu, também, princípios norteadores gerais, as atribuições do CNJ e dos Tribunais de Justiça, nesse processo de implantação da justiça restaurativa judicial no Poder Judiciário brasileiro. Considerou ainda, referenciais importantes que deverão nortear os processos de formação de facilitadores, que emergirão a partir dessa regulamentação. 
Nesse contexto, no ano de 2015, a justiça restaurativa completou 10 anos de discussão e início de sua implantação no Brasil, e, neste momento, encontra-se em acelerado processo de reconhecimento de sua configuração como uma alternativa humanizada de pacificação social, visando, principalmente, o fortalecimento do diálogo entre as pessoas e o protagonismo na resolução de seus conflitos, bem como a busca da justiça como valor. A justiça restaurativa encontra-se em intenso processo de implantação no contexto brasileiro, o qual está demandando e demandará, ainda, diversificados estudos, reflexões, pesquisas teórico-metodológicas, práticas e empíricas, no sentido de identificar quais as suas peculiaridades, potencialidades e entraves. Com esses estudos e/ou reconhecimentos, as adversidades e lacunas poderão ser reconhecidas e enfrentadas, a partir da implantação dessa nova forma e visão na abordagem dos conflitos, e de uma diferente concepção de justiça para a proposição de novas políticas judiciárias de atenção e resolução dos conflitos no país.

\section{A Justiça Restaurativa no Estado do Rio Grande do Sul}

A implantação da justiça restaurativa no Estado do Rio Grande do Sul foi pioneira no Brasil, e contou, inicialmente, com a importante intermediação da Escola Superior da Magistratura (ESM) da Associação dos Juízes do Rio Grande do Sul (Ajuris), que, desde o ano de 2005, difundiu e apoiou o início das discussões sobre essa temática, e, inclusive, disponibilizou as primeiras formações na cidade de Porto Alegre (RS). A realização dessas atividades em solo gaúcho, também envolveu diversas parcerias, dentre as quais se destaca a execução do projeto "Promovendo Práticas Restaurativas no Sistema de Justiça Brasileiro", em parceria com a Secretaria da Reforma do Judiciário (SRJ) do Ministério da Justiça (MJ), e com o Programa das Nações Unidas (PNUD). Como resultado teórico deste momento, foram editadas duas importantes publicações, na área da justiça restaurativa, com importantes sistematizações relacionadas a essas experiências pilotos, quais sejam: as "Novas Direções na Governança da Justiça e Segurança" (MJ/SRJ 2006); e a “Justiça Restaurativa: Coletânea de Artigos” (MJ/SRJ 2005).

Dessa experiência piloto de implantação das práticas restaurativas em Porto Alegre (RS), que envolveu servidores(as) e magistrados(as) do Poder Judiciário gaúcho, além de outros(as) parceiros(as) locais envolvidos(as) com o tema da justiça restaurativa, 
sobreveio a formalização da Central de Práticas Restaurativas (CPR), junto à estrutura do Poder Judiciário do RS, vinculada ao 3ํ Juizado da Infância e Juventude (JIJ) da Comarca de Porto Alegre(RS). Essa formalização sucedeu-se por iniciativa da Corregedoria Geral de Justiça (CGJ), e por meio da aprovação da Resolução do Conselho da Magistratura (Comag) do $T J / R S$ no 822 , em 08 de fevereiro de 2010. Esta regulamentação desencadeou o início da aplicação formalizada das práticas restaurativas no âmbito da execução dos processos judiciais, que envolviam as Medidas Socioeducativas, aplicadas aos atos infracionais praticados pelos(as) adolescentes em conflito com a lei ${ }^{2}$.

Nesse sentido, e dando continuidade à institucionalização e fortalecimento da justiça restaurativa no Poder Judiciário do RS, em 19 de agosto de 2014, foi aprovada a Resolução no 1.026/2014 do Comag TJ/RS ${ }^{3}$ que disciplinou os Centros Judiciários de Resolução de Conflitos e Cidadania (Cejuscs), no âmbito do Tribunal de Justiça do Estado do Rio Grande do Sul. Esse regulamento elencou, também, normas inerentes à justiça restaurativa no TJRS, e indicou as metodologias propostas para esta área, como umas das alternativas a constarem no rol dos serviços a serem ofertados pelos Cejuscs gaúchos, como forma de prevenção, tratamento e solução de conflitos, estejam judicializados ou não. Também, em outubro de 2014, a justiça restaurativa passou a ser institucionalizada como uma política judiciária estratégica do Tribunal de Justiça do RS, por meio da aprovação, pelo Comag, do parecer da Corregedoria-Geral de Justiça (CGJ), que propôs a criação do Programa Justiça Restaurativa para o Século 21 do Tribunal de Justiça do Estado do Rio Grande do Sul (JR21 TJRS), sobre o qual passaremos a discorrer especificamente a seguir.

\footnotetext{
${ }^{2}$ As Medidas Socioeducativas foram instituídas pelo artigo 112 da Lei Federal ํㅡ‥069, de 13 de julho de 1990 - Estatuto da Criança e do Adolescente (ECA), e regulamentadas especificamente pela Lei Federal no 12.594 , de 18 de janeiro de 2012, que instituiu o Sistema Nacional de Atendimento Socioeducativo (Sinase).

${ }^{3} \mathrm{Em} 26$ de fevereiro de 2016, foi editada a Resolução do COMAG TJRS № 1.124, que alterou a Resolução COMAG TJRS № 1.026/2014, inserindo a Justiça Restaurativa como uma metodologia a ser observada pelos Cejuscs. Em face dessa atualização, a Central de Práticas Restaurativas (CPR) do Juizado da Infância e Juventude de Porto Alegre (JIJ) foi extinta, e passou a denominar-se CEJUSC Práticas Restaurativas, estando a partir de então, vinculada ao CEJUSC da Comarca de Porto Alegre.
} 


\section{O Programa Justiça Restaurativa para o Século 21 do Tribunal de Justiça do Estado do Rio Grande do Sul (JR21 TJRS)}

\subsection{Dos objetivos geral e específicos do programa:}

O Programa Justiça Restaurativa para o Século 21 do Tribunal de Justiça do Estado do Rio Grande do Sul (JR21 TJRS) foi instituído nos autos do expediente administrativo no 0010-14/003022-8, em sessão do Egrégio Conselho da Magistratura (Comag), de 21 de outubro de 2014, na qual foi aprovado o parecer da Corregedoria-Geral de Justiça (CGJ), propondo a criação de um projeto especial com a seguinte função:

[...] o propósito de difundir, de implantar, de aprimorar e de consolidar a Justiça Restaurativa no Primeiro Grau da Justiça Estadual (...), tendo por escopo o planejamento de uma estratégia de implantação e de utilização do paradigma restaurativo em ramos especiais da prestação jurisdicional, tais como na Infância e Juventude, na Violência Doméstica e Familiar contra a Mulher, na Execução Penal, no Direito de Família e no Direito Penal. (Fonte: TJRS. Documento-base Programa JR21 p. 5)

Conforme registrado no documento-base do Programa JR21 TJRS, seu objetivo geral é "Promover estratégias de pacificação social baseadas na difusão dos princípios e no desenvolvimento das práticas restaurativas para prevenção e transformação construtiva de conflitos em âmbito judicial e extrajudicial”. E especificamente:

a) Desenvolver as práticas de Justiça Restaurativa em Unidades Jurisdicionais de Referência no âmbito do Poder Judiciário do Rio Grande do Sul e referenciar sua difusão nas demais políticas públicas e nas comunidades;

b) Consolidar a aplicação do enfoque e das práticas restaurativas na jurisdição da infância e da juventude, já em desenvolvimento no âmbito judicial do Rio Grande do Sul, conforme Resolução do Comag TJRS nำ822/2010;

c) Desenvolver expertise para aplicação das práticas restaurativas em áreas jurisdicionais ainda não exploradas, em especial na violência doméstica, juizados especiais criminais e execuções penais;

d) Viabilizar a oferta de práticas restaurativas como parte da oferta de serviços de soluções autocompositivas nos Centros Judiciários de Solução de Conflitos e Cidadania do Rio Grande do Sul (Cejuscs); 
e) Produzir e difundir conhecimentos, capacitando recursos humanos para a atuação em práticas da Justiça Restaurativa e em sua multiplicação;

f) Apoiar a utilização do enfoque e das práticas restaurativas no âmbito de políticas e serviços a cargo do poder executivo, notadamente nas áreas de segurança, assistência social, educação e saúde;

g) Apoiar a criação e consolidação de serviços de base comunitária para pacificação de conflitos com base nos princípios e práticas da justiça restaurativa.

Neste contexto, relevante destacar que, embora a implantação da justiça restaurativa no TJRS tenha se efetivado mediante a proposta de testagem de projetos-pilotos em diferentes áreas de intervenção (infância e juventude, violência doméstica, execução criminal, penas e medidas alternativas, varas de família, juizado especial criminal, Cejusc), seu foco principal sempre esteve pautado na efetivação das práticas restaurativas nos Cejuscs, ambiente já reconhecido como o mais adequado para a implantação destas práticas.

Também a justiça restaurativa amplia o olhar da justiça tradicional para o horizonte de busca para a busca da justiça como valor. E desta forma passa a se efetivar muito mais do que uma ferramenta metodológica de solução de conflitos, e sim com uma visão sistêmica do conflito

Portanto, mais do que objetivar alternativas de solução autocompositivas, a Justiça Restaurativa tende à resolução do conflito ou situaçãoproblema subjacente, numa visão sistêmica -o que significa atuar em rede, promover transformações nos ambientes institucionais e comunitários e, sempre que possível, evitar a judicialização ou restituir a capacidade de solução de conflitos aos próprios atores, em seus contextos de origem. Diz-se sistêmica uma abordagem capaz de identificar as diversas partes fracionárias de um conjunto, relacionando-as simultaneamente com ele, de modo a compreendê-las sempre como interdependentes do sistema como um todo. Essa compreensão sistêmica deve orientar o olhar, seja com relação às situações de conflito em si, seja com relação ao contexto em que será buscada a solução. (BRANCHER, Leoberto; FLORES, Ana Paula. 2016. p. 99)

\subsection{Das unidades judiciárias do Poder Judiciário do RS com implantação das práticas restaurativas}

Desde a sua criação, em outubro de 2014, o TJRS, por meio do Programa JR21, iniciou o processo de implantação das práticas restaurativas em unidades judiciárias e 
administrativas conforme a tabela 1.

Relevante destacar que, além das comarcas supramencionadas, que passaram a implantar as práticas restaurativas a partir da aprovação do Programa JR21 TJRS, duas outras unidades judiciárias já realizam práticas restaurativas, como ambientes de experimentação, anteriormente à implantação do programa. Tratam-se do Cejusc Caxias do Sul e da CPR do Juizado da Infância e Juventude, posteriormente de nominado Cejusc Porto Alegre - Práticas Restaurativas. Desta forma, totalizam-se 36 unidades judiciárias, no TJRS, com práticas restaurativas implantadas e/ou em implantação até o momento.

Ainda, pode-se afirmar que a implantação das práticas restaurativas em unidades judiciárias no ano de 2015, e em 2016, estiveram em consonância com a proposta da "Meta 8", definida pelo CNJ, para cumprimento por parte dos tribunais brasileiros em relação à justiça restaurativa. A "Meta 8" consistia em: "Implementar práticas de Justiça Restaurativa (Justiça Estadual): Implementar projeto com equipe capacitada para oferecer práticas de Justiça Restaurativa, implantando ou qualificando pelo menos uma unidade para esse fim, até 31.12.2016".

A meta em questão foi incluída dentre as metas do Poder Judiciário brasileiro no 9 Encontro Nacional do Poder Judiciário, realizado em Brasília, nos dias 24 e 25 de novembro de 2015. Nesse encontro foram aprovadas 08 metas nacionais específicas para os diversos segmentos da Justiça, e, dentre elas como novidade a meta relacionada à justiça restaurativa. O TJRS, com base nos dados informados e apurados pelo CNJ neste período teve o reconhecimento de alcance de $100 \%$ da meta no ano de 2016 .

\subsection{Do processo de formação em Justiça Restaurativa do Programa JR21 TJRS:}

O processo de formação na área da Justiça Restaurativa no TJRS, foi regulamentado por meio da Resolução do Comag n 1.125, de 15 de março de 2016, que aprovou a Formação Integral em Justiça Restaurativa e Construção de Paz do Programa JR21 TJRS. Esta resolução restou fundamentada pela aprovação, por parte do Núcleo Permanente de Métodos Consensuais de Conflitos (Nupemec) do TJRS, em sessão de 08 de setembro de 2015, da proposta de Formação Integral em Justiça Restaurativa do TJRS, de autoria do magistrado Leoberto Brancher - Acórdão nํㅜ5997-15/000202-2.A formação do TJRS definiu como metodologia de implementação da justiça restaurativa, neste 
Tabela 1. Unidades judiciárias e administrativas do TJRS em que foram implantadas as práticas restaurativas em 2015, 2016, 2017/2018

\begin{tabular}{|c|c|c|c|}
\hline Ano & $\begin{array}{c}\text { Unidades } \\
\text { judiciárias/ } \\
\text { Administrativas }\end{array}$ & Comarcas & Áreas de abrangência \\
\hline 2015 & 12 & $\begin{array}{l}\text { Porto Alegre, Caxias do Sul, } \\
\text { Novo Hamburgo, Pelotas, } \\
\text { Passo Fundo, Lajeado, Santa } \\
\text { Maria, Sapiranga e Guaíba }\end{array}$ & $\begin{array}{c}\text { Cejusc, Violência } \\
\text { Doméstica, Execuções } \\
\text { Criminais, Penas e } \\
\text { Medidas Alternativas, } \\
\text { Infância e Juventude, } \\
\text { Família e Juizado Especial } \\
\text { Criminal. }\end{array}$ \\
\hline \multirow[t]{2}{*}{2016} & 08 & $\begin{array}{l}\text { Santana do Livramento, } \\
\text { Taquara, Gravataí, São } \\
\text { Leopoldo, São Borja, } \\
\text { Pelotas, Novo Hamburgo, } \\
\text { Santa Cruz do Sul. }\end{array}$ & $\begin{array}{c}\text { Cejusc, Violência } \\
\text { Doméstica, Infância e } \\
\text { Juventude. }\end{array}$ \\
\hline & 01 & Porto Alegre & $\begin{array}{c}\text { Áreas administrativas } \\
\text { do TJRS - Servidores } \\
\text { da Paz }\end{array}$ \\
\hline $2017 / 2018$ & 13 & $\begin{array}{l}\text { Bento Gonçalves, Canoas, } \\
\text { Erechim, Gravataí, Guaíba, } \\
\text { ljuí, Montenegro, Porto } \\
\text { Alegre, Rio Grande, Santa } \\
\text { Rosa, Santo Ângelo, São } \\
\text { Leopoldo, Uruguaiana. }\end{array}$ & Cejuscs \\
\hline Total & 34 & Capital e 33 comarcas & \\
\hline
\end{tabular}

Fonte:Tribunal de Justiça do Estado do Rio Grande do Sul- Dados de Agosto/2018

momento, os círculos de construção de paz, idealizados pela professora norte-americana Kay Pranis.

A Formação Integral em Justiça Restaurativa do Programa JR21 TJRS, iniciada 
no ano de 2015, estruturou-se por meio das atividades formativas descritas na tabela 2.

Quando passamos a relatar este tema, é conveniente pontuar que, o Estado do Rio Grande do Sul, durante suas atividades protagonistas de implantação da justiça restaurativa no Brasil, articulou e viabilizou, por meio da escola da magistratura gaúcha, a recepção da professora norte-americana Kay Pranis, a partir do ano de 2010. Com a vinda da professora Kay, nesta época, foi possível dar início ao processo de formação de um grupo de facilitadores(as), e em 2012 de instrutores(as), que foram legitimados(as) para realizar a formação de outros(as) facilitadores(as) em solo brasileiro. Mas, relevante destacar, também, que o número de instrutores(as) formados(as), ainda ficou bem restrito, e estes(as) profissionais passaram a atuar em formações no Rio Grande do Sul, e em outros estados do Brasil.

Neste contexto, o TJRS, em função de reordenamentos em seus processos de gestão e execução de suas atividades formativas, deliberou que, a partir do ano de 2016 , a modalidade de contratação para instrutores(as), supervisores(as) e/ou tutores(as) externos(as) ao Poder Judiciário gaúcho, se efetivaria por meio de editais de credenciamento, e não mais na forma de convênios. Os editais de credenciamento do TJRS, com fundamento legal no artigo 25 da Lei no 8.866, de 21 de junho de 1993, que instituiu normas para licitações e contratos da Administração Pública, foram operacionalizados pelo Departamento de Compras (DEC) do TJRS. Os editais de credenciamento tiveram como objeto:

\begin{abstract}
"Credenciamento de instrutor, supervisor e tutor para atuarem nas atividades formativas de Facilitadores Judiciais de Círculos de Justiça Restaurativa e de Construção de Paz, bem como de Lideranças Restaurativas, em conformidade com as regulamentações da Formação Integral em Justiça Restaurativa e Construção de Paz, do Programa Justiça Restaurativa para o Século 21 do Tribunal de Justiça do Estado do Rio Grande do Sul (JR21 TJRS), previstas na Resolução no 1.125, de 14 de março de 2016, do Conselho da Magistratura (COMAG), e em outras unidades judiciárias mediante definição da administração do Tribunal de Justiça do Estado do Rio Grande do Sul (TJRS)" (Fonte: TJRS)
\end{abstract}

Também, como parte do reordenamento das formação e gestão de pessoas, o Poder Judiciário do RS criou o Centro de Formação de Desenvolvimento de Pessoas do Poder Judiciário Estadual (CJud PJRS), por meio de Ato da Presidência do TJRS no 041/2015-P, de 07 de outubro de 2015. A criação do CJud buscou atender a necessidade 
Tabela 2. Etapas da Formação Integral em Justiça Restaurativa do TJRS - Resolução Comag no 1.125/2016

\begin{tabular}{|c|c|c|c|}
\hline & Atividades formativas & Carga Horária & Modalidade \\
\hline 1 & $\begin{array}{l}\text { Oficinas de Planejamento e Gestão - } \\
\text { Metodologia Dragon Dreaming }\end{array}$ & 10 horas-aula & Presencial \\
\hline 2 & $\begin{array}{c}\text { Curso de Formação de Facilitadores } \\
\text { Judiciais de Círculos de Justiça } \\
\text { Restaurativa e de Construção de Paz e } \\
\text { Lideranças Restaurativas }\end{array}$ & 40 horas-aula & Presencial \\
\hline 3 & $\begin{array}{c}\text { Curso de Formação Teórico-Prático em } \\
\text { Justiça Restaurativa }\end{array}$ & 40 horas-aula & A distância \\
\hline 4 & $\begin{array}{c}\text { Estágio Prático na Facilitação de Círculos } \\
\text { de Justiça Restaurativa e de Construção } \\
\text { de Paz }\end{array}$ & 40 horas-aula & A distância \\
\hline \multirow[t]{2}{*}{5} & $\begin{array}{l}\text { Atividades Práticas (Entrega de } 10 \text { relatórios } \\
\text { práticos de círculos de construção de paz } \\
\text { realizados ( } 05 \text { conflitivos e } 05 \text { não conflitivos) }\end{array}$ & $\begin{array}{l}100 \text { horas-aula } \\
\text { (aproximada- } \\
\text { mente) }\end{array}$ & Misto \\
\hline & Carga Horária total & 230 Horas-aula & \\
\hline 6 & $\begin{array}{c}\text { Curso Formação de } \\
\text { Instrutores-Supervisores em Justiça } \\
\text { Restaurativa }\end{array}$ & 40 horas-aula & Presencial \\
\hline \multirow[t]{2}{*}{7} & $\begin{array}{c}\text { Estágio Prático como na Formação de } \\
\text { Instrutores-Supervisores em Justiça } \\
\text { Restaurativa }\end{array}$ & 40 horas-aula & Presencial \\
\hline & Carga Horária total & 80 horas-aula & \\
\hline
\end{tabular}

Fonte:Tribunal de Justiça do Estado do Rio Grande do Sul - Resolução Comag no $1.125 / 2016$. 
de formação permanente de magistrados(as) e servidores(as) do TJRS, e ainda, de desenvolver corpo docente interno, conforme recomendações do CNJ. As recomendações do CNJ, emanaram das Resoluções nำ 159, de 12 de novembro de 2012, que definiu diretrizes administrativas e financeiras para a formação de pessoas no Poder Judiciário brasileiro; e no 192, de 08 de maio de 2014, que preconizou que as ações de aperfeiçoamento de magistrados(as) e servidores(as) sejam desenvolvidas por corpo docente interno.

A partir destas mudanças no TJRS, o CJud PJRS, enquanto escola judicial, passou a ser o órgão competente pela coordenação pedagógica dos cursos de formação na área da justiça restaurativa, bem como o gestor e executor das ações de formação previstas nos editais de credenciamento n0 01/2016-DEC e nำ02/2017-DEC.

Desta forma, as atividades formativas previstas pelo Programa JR21, desde sua concepção, em outubro de 2014, e previstas na Resolução do Comag nำ1.125/2016 Formação Integral em Justiça Restaurativa e Construção de Paz, foram agregadas ao planejamento anual de cursos do CJud, bem como os recursos previstos para o financiamento destas ações, foram previstos em dotações orçamentárias destinadas às formações da área da justiça restaurativa. Estas ações efetivaram um dos objetivos principais do Programa JR21, enquanto projeto-piloto, que foi o da institucionalização da justiça restaurativa como política judiciária.

\subsection{Da institucionalização da justiça restaurativa como política judiciária no TJRS}

A institucionalização da justiça restaurativa como política judiciária no Tribunal de Justiça do Estado do Rio Grande do Sul, teve seu início demarcado pela aprovação do Programa JR21, em outubro de 2014, com o objetivo principal:

Promover estratégias de pacificação social baseadas na difusão dos princípios e no desenvolvimento das práticas restaurativas para prevenção e transformação construtiva de conflitos em âmbito judicial e extrajudicial. (Fonte: Documento-base do Programa JR21 TJRS pág. 23)

A partir desta aprovação, a implantação das práticas restaurativas passou a integrar os objetivos estratégicos previstos no Mapa Estratégico do Tribunal de Justiça do Estado do Rio Grande do Sul 2016 - 2020. 
Também, a partir de maio de 2015 iniciou-se o processo de formação de facilitadores(as) judiciais, conforme atividades previstas na Resolução do Comag no 1.125/2016 - Formação Integral em Justiça Restaurativa e Construção de Paz, que prosseguem em execução até o momento atual, por meio da gestão e coordenação pedagógica do CJud PJRS.

Dando vazão às recomendações nacionais acerca da implantação das práticas restaurativas no Poder Judiciário, o Programa JR21 do TJRS, passou a ser coordenado pelo Núcleo Permanente de Métodos Consensuais de Solução de Conflitos (Nupemec TJRS), a partir de $1^{\circ}$ de junho de 2017, conforme deliberação do Comag na sessão de 23 de maio de 2017, formalizada no Edital oㅡ 55, de 24 de maio de 2017. A implantação das práticas restaurativas no TJRS, por meio do Programa JR21, foi coordenada pelo magistrado Leoberto Brancher, de 21 de outubro de 2014 até 31 de maio de 2017.

O reordenamento na coordenação do Programa JR21, foi fundamentado, principalmente, nas recomendações emitidas pelo Fórum Nacional de Mediação e Conciliação (Fonamec) - Recomendação no 01, de 07 de abril de 2017, que dentre importantes orientações orientou em seu artigo $1^{\circ}$ que:

\footnotetext{
Implementem a Política Nacional de Justiça Restaurativa, de que trata a Resolução no 225/16 do Conselho Nacional de Justiça, em colaboração com a Política Nacional de Solução Adequada de Conflitos de que trata a Resolução no 125/2010 do CNJ, por intermédio do sistema dos Núcleos Permanentes de Métodos Consensuais de Solução de Conflitos NUPEMECS e Centros Judiciários de Solução de Conflitos e Cidadania - CEJUSCS.
}

Com esta alteração na coordenação do Programa JR21, as formações na área da justiça restaurativa permaneceram sob a gestão e coordenação pedagógica do CJud PJRS, mas, as demais atribuições relacionadas ao monitoramento, assessoramento, gestão de dados e resultados das práticas restaurativas, etc., no âmbito dos Cejuscs, passou a ser atribuição do Nupemec, da mesma forma que é realizada para os demais métodos autocompositivos de solução de conflitos.

Neste contexto, a justiça restaurativa prossegue em processos de ajustamentos nos ritos de gestão administrativa, financeira e de outros fluxos necessários à acomodação desta nova visão de justiça nos ritos judiciais tradicionais. Prosseguem, também, alguns ajustes normativos no TJRS, os quais podem ser citados: a) Resolução no 02 do 
Órgão Especial, de 07 de agosto de 2018, que alterou a Resolução ㄲo 04/2012 do mesmo órgão, que promoveu alterações na composição e atribuições do Nupemec TJRS, e criou as Coordenadorias de Conciliação e Mediação de $1^{\circ}$ e $2^{\circ}$ Graus e Justiça Restaurativa, com o principal objetivo de fundamentar e instrumentalizar os(as) membros do núcleo, no processo de tomada de decisões em cada área temática; b) Resolução № 1.219 do Comag, de 09 de agosto de 2018, que revogou a Resolução no 822/2010 do Comag, que criou a Central de Práticas Restaurativas dos Juizados da Infância e Juventude de Porto Alegre, e redefiniu sua nomenclatura para Centro Judiciário de Solução de Conflitos e Cidadania - Cejusc/Poa Justiça Restaurativa do Foro Central Prédio I. Este Cejusc passa a ser configurado como um "Cejusc temático", conforme autoriza a Resolução CNJ no 125/2010; e c) Resolução no 03, do Órgão Especial, de 14 de agosto de 2018, que alterou a Resolução no 04/2012 do mesmo órgão, e incluiu na estrutura do Nupemec TJRS, uma assessoria técnica e uma secretaria, com o fim específico de fortalecer a atuação do núcleo na execução das competências que the atribuem a resolução que o instituiu. Relevante destacar que, a Resolução do Comag no 1.125/2016, que trata da Formação Integral em Justiça Restaurativa e Construção de Paz também encontra-se em processo de atualização, em face da necessidade de adequar algumas alterações pedagógicas da formação, bem como conceituais e de certificação.

Neste contexto, é possível afirmar que, a implantação da justiça restaurativa no TJRS tem se delineado em diversas etapas, desde o início da aprovação do Programa JR21, em outubro de 2014. A maioria destas etapas já se incluíram na rotina do tribunal gaúcho, principalmente as que se referem às rotinas administrativas e orçamentárias. Mas, de igual importância, o acompanhamento pedagógico de equipe da unidade que equivale à escola judicial CJud PJRS, foi um grande diferencial no aprimoramento e reconhecimento da formação até o momento. É fato que, restam desafios, mas o caminho percorrido é de importante relevância para a efetivação das práticas restaurativas na rotina do judiciário gaúcho.

\subsection{CONSIDERAÇÕES FINAIS}

Para que a justiça restaurativa se efetive como uma política judiciária no tribunal gaúcho, muitas etapas do caminho institucional e administrativo já foram percorridas, 
com a superação de dificuldades e com a proposição de desafios a serem planejados.

A aprovação do Programa JR21, com certeza, foi um divisor de águas na história já construída da justiça restaurativa no Estado do Rio Grande do Sul, e especialmente no Poder Judiciário do RS, em primeiro lugar, por resgatar os capítulos protagonistas de sua implantação, quando ainda não havia nenhuma regulamentação nacional sobre o tema, seja interna do TJRS, ou externamente, de outros órgãos competentes para tal. Em segundo lugar, pelo fato de que, durante o processo de implantação da justiça restaurativa, até então fundamentada em normativas internas do tribunal gaúcho, sobreveio a regulamentação nacional, no caso a Resolução do CNJ № 225/2016, o que acarretou a necessidade de ajustes e novas reflexões sobre o assunto.

As dificuldades que se demonstraram referem-se, principalmente, às novidades em implantar serviços judiciais, diferentes dos tradicionais, a serem ofertados nas unidades judiciais, mas também da necessária mudança de visão, sejam dos(as) magistrados(as), servidores(as) e de outros atores envolvidos(as) pela nova percepção da justiça, enquanto valor. Essa visão, enseja um novo arranjo institucional para a implantação da cultura do diálogo e de práticas dialógicas e humanizadas, que desacomodam as estruturas já instaladas.

Mas, de outra forma, o processo de implantação das práticas restaurativa no TJRS demonstrou-se desafiador e pioneiro, também, pois todo o processo de institucionalização, bem como de formação esteve pautado na testagem dos ritos e das atividades formativas. Com relação às atividades formativas, foi e será ainda mais desafiador, pois a formação integral em justiça restaurativa, embora densa e vastamente fundamentada e acompanhada pedagogicamente, não se ampara, ainda, em nenhuma referência de formação básica, regulada pelo $\mathrm{CNJ}$, por exemplo. Por certo o órgão irá regulamentar o tema, principalmente depois da pesquisa recentemente publicada em 2018, denominada "Justiça Restaurativa: Pilotando a Justiça Restaurativa: O papel do Poder Judiciário", de sua iniciativa. A pesquisa refere importantes elementos para a regulamentação da justiça restaurativa, bem como pontos importantes a serem observados no processo de formação de seus(suas) operadores(as).

Nesse sentido, o processo de implantação prossegue registrando alguns indica- 
tivos importantes, tais como: a necessidade do prosseguimento das implantações; a ampliação e qualificação dos processos formativos, sejam de forma presencial e/ou a distância, no que couber. Também, a partir da interação de todas as unidades implantadas e em implantação, poderá propor-se a definição de fluxos e padronização de procedimentos dos atendimentos nas unidades judiciárias locais - Cejuscs, que concentram o suporte operacional das atividades relacionadas à gestão, execução e monitoramento das práticas que envolvem os métodos adequados de solução de conflitos. Estas providências têm como foco principal a uniformização das atividades que envolvem a realização de práticas restaurativas, e que, também possam assegurar a difusão da justiça restaurativa no $\mathrm{RS}$ e no Brasil, de forma qualificada, e possa se consolidar em consonância com os seus valores e princípios estruturantes.

Ainda que, já é possível se vislumbrar que, para a justiça restaurativa poder contar com uma implantação qualificada no RS, especialmente a partir de suas experiências práticas, deverá contar com processos formativos, realizados de forma sistemática, qualificada, e pedagogicamente amparados. Fundamentalmente, deve envolver magistrados(as), servidores(as) do Poder Judiciário, e outros(as) atores da sociedade civil parceiros(as) que estejam envolvidos(as) na execução das atividades de implantação e atendimento.

Relevante destacar que, como a vinculação institucional dos facilitadores(as) judiciais de círculos de construção de paz, formados e em formação, até o momento, não é de exclusiva com o Poder Judiciário do RS, há que se considerar a ocorrência de uma evasão significativa destes(as) facilitadores(as) da atuação prática, indicando a necessidade de avaliar e/ou reavaliar a forma e os critérios de seleção para as formações, para que o processo de implantação não reste prejudicado, visto estes(as) serem os(as) protagonistas das ações de atendimentos.

Diante deste contexto, somente um processo de formação consistente em relação aos conteúdos e às metodologias elencadas para atendimento, aliado aos processos de monitoramento e avaliação que possam mensurar resultados quantitativos e qualitativos da efetiva implantação e implementação da justiça restaurativa no RS e no Brasil, poderão assegurar a boa execução dessa política pública judiciária. 
Porém, com a publicação da regulamentação da Política Nacional de Justiça Restaurativa, no âmbito do Poder Judiciário, pelo CNJ, em 31 de maio de 2016, tanto os processos de formação, quanto de institucionalização das rotinas administrativas e/ou judiciárias, adquirem um caráter mais formalizado, mesmo que ainda pendentes de detalhamentos, que talvez dependam mais de tribunal, observadas as suas peculiaridades. Mas, que, as práticas restaurativas, quando institucionalizadas, pelo Poder Judiciário, possam influenciar na satisfação das necessidades de todos(as) os(as) partícipes. E assim, possam, de fato e direitos, contribuir com as perspectivas de pacificação social que se vislumbra para o Estado do Rio Grande do Sul, para o Brasil e para o mundo. Embora singela a contribuição com o relato desta experiência prática, é muito gratificante escrever e descrever sobre o início de uma história de mudanças, muitas ressignificações do que é e do que se espera que seja a justiça como um valor.

\section{Referências}

BRASIL. Constituição Federal de $1988 . \quad$ Disponível em:http://www.planalto.gov.br/ccivil_03/Constituicao/Constituicao.htm>text Acesso em out. 2018.

—. Lei Federal № 8.666, 21 de junho de 1993. Lei de Licitações. Disponível em: <http://www.planalto.gov.br/ccivil_03/LEIS/L8666cons.htm> Acesso em out. 2018.

- Lei Federal № 8.069, de 13 de julho de 1990. Estatuto da Criança e Adolescente. Disponível em: <http://www.planalto.gov.br/ccivil_03/LEIS/L8069.htm> Acesso em out. 2018.

- Lei Federal № 13.105, de 16 de março de 2015. Novo Código de Processo Civil. Disponível em: <http://www.planalto.gov.br/ccivil_03/_Ato20152018/2015/Lei/L13105.htm> Acesso em out. 2018.

—. Lei Federal № 13.140, de 26 de junho de 2015. Lei da Mediação. Disponível em: <http://www.planalto.gov.br/ccivil_03/_ato2015-2018/2015/Lei/L13140.htm> Acesso em out. 2018.

- Conselho Nacional de Justiça (CNJ). Resolução $n^{\circ}$ 125, de 29 de novembro de 2010. Dispõe sobre a Política Judiciária Nacional de tratamento adequado dos conflitos de interesses no âmbito do Poder Judiciário e dá outras providências Disponível em: <http://www.cnj.jus.br/busca-atos-adm?documento=2579 >. Acesso em out. de 2018.

- Conselho Nacional de Justiça (CNJ). Resolução no 159, 12 de novembro de 2012. Dispõe sobre as diretrizes administrativas e financeiras para a formação de magistrados e servidores do Poder Judiciário. Disponível em: <http://www.cnj.jus.br/atosnormativos?documento=972> Acesso em out. de 2018.

—. Conselho Nacional de Justiça (CNJ). Resolução no 192, de 08 de maio de 2014. 
Dispõe sobre Política Nacional de Formação e Aperfeiçoamento dos Servidores do Poder Judiciário. Disponível em: <http://www.cnj.jus.br/images/resol_gp_192_2014.pdf>. Acesso em out. 2018.

- Conselho Nacional de Justiça (CNJ). Resolução nº 225, de 31 de maio de 2016. Dispõe sobre a Política Nacional de Justiça Restaurativa no âmbito do Poder Judiciário e dá outras providências. Disponível em: <http://www.cnj.jus.br/atosnormativos?documento=2289 $>$ Acesso out. 2018.

FLORES, Ana Paula Pereira. BRANCHER, Leoberto. O Programa Justiça Restaurativa para o Século 21. In: CRUZ, Fabrício Bittencourt da (Coord.). Justiça Restaurativa: horizontes a partir da Resolução CNJ 225. Brasília: CNJ, 2016. Disponível em: <http://www.cnj.jus.br/files/conteudo/arquivo /2016/08/4d6370b2cd6b7ee42814ec39946f9b67.pdf> Acesso em out. 2018.

FONAMEC. Fórum Nacional de de Mediação e Conciliação. Recomendação no 01 , de 07 de abril de 2017. Disponível em: <http://fonamec.tjrj.jus.br/conteudo/documentos/Recomendacao_n_01-2017FONAMEC.pdf>. Acesso em out. 2018.

-. Ministério da Justiça (MJ). Secretaria da Reforma do Judiciário. Novas Direções na Governança da Justiça e da Segurança. 2006. Disponível em:<http://www.justica.gov.br/sua-seguranca/seguranca-publica/analise-epesquisa/download/outras_publicacoes/pagina-1/14governanca-na-seguranca-materialdo-mj.pdf>. Acesso em out. 2018.

-. Ministério da Justiça (MJ). Secretaria da Reforma do Judiciário. Justiça Restaurativa: Coletânea de Artigos. 2006. Disponível em: <http://www.undp.org/content/dam/aplaws/publication/en/publications/democraticgovernance/dg-publications-for-website/justica-restaurativa-restorative-justice/Justice_Pub_Restorative\%20Justice.pdf>. Acesso em out. de 2018.

INSTITUTO LATINO AMERICANO DAS NAÇÕES UNIDAS PARA A PREVENÇÃO DO DELITO E TRATAMENTO DO DELINQÜENTE/ BRASIL (ILANUD/BRASIL). Sistematização e Avaliação de Experiências em Justiça Restaurativa. 2006. Disponível em <https://erc.undp.org/evaluation/documents/download/3752>. Acesso em out. 2018.

MARSHALL, Tony F. Restorative Justice - An overview. 1999. Disponível em: $<$ http://fbga.redguitars.co.uk/restorativeJusticeAnOverview.pdf >. Acesso em out. de 2018.

ORGANIZAÇÕES DAS NAÇÕES UNIDAS. Conselho Econômico e Social. Resolução no 1.999/26, de 28 de julho de 1999: que dispõe sobre a "Elaboração e aplicação de medidas de mediação e justiça restaurativa em matéria de justiça criminal". Disponível em <http://www.unric.org/pt/actualidade/5688>. Acesso em out. de 2018.

ORGANIZAÇÕES DAS NAÇÕES UNIDAS. Conselho Econômico e Social. Resolução no 2.000/14, de 27 de julho de 2000: que dispõe sobre os "Princípios básicos sobre a utilização de programas de justiça restaurativa em matéria criminal". Disponível em <http://www.unric.org/pt/actualidade/5688 >. Acesso em out. de 2018.

ORGANIZAÇÕES DAS NAÇÕES UNIDAS. Conselho Econômico e Social. Resolu- 
ção no 2.002/12, de 24 de julho de 2002: que definiu "Princípios básicos para a utilização de Programas de Justiça Restaurativa em matéria criminal" Disponível em <http://www.unric.org/pt/actualidade/5688 >. Acesso em out. de 2018.

RIO GRANDE DO SUL. Tribunal de Justiça do Estado do Rio Grande do Sul. Conselho Magistratura (Comag). Resolução nํ 822, de 05 de fevereiro de 2010. Declara a existência da Central de Práticas Restaurativas junto ao Juizado da Infância e Juventude da Comarca de Porto Alegre, estabelecendo indicadores para o monitoramento do trabaIho desenvolvido. Disponível em <http://www.tjrs.jus.br/site/publicacoes/administrativa/>. Acesso em out. de 2018.

RIO GRANDE DO SUL. Tribunal de Justiça do Estado do Rio Grande do Sul. Resolução Órgão Especial no 004, de 09 de abril de 2012. Disponível em $<$ http://www.tjrs.jus.br/site/publicacoes/administrativa/>. Acesso em out. de 2018.

RIO GRANDE DO SUL. Tribunal de Justiça do Estado do Rio Grande do Sul. Resolução Órgão Especial nํㅜ 04, de 09 de abril de 2012. Institui o Núcleo Permanente de Métodos Consensuais de Solução de Conflitos (Nupemec). Disponível em <http://www.tjrs.jus.br/site/publicacoes/administrativa/>. Acesso em out. de 2018

RIO GRANDE DO SUL. Tribunal de Justiça do Estado do Rio Grande do Sul. Resolução Órgão Especial no 02, de 07 de agosto de 2018. Altera dispositivos da Resolução Órgão Especial no 04/2012 que criou o Núcleo Permanente de Métodos Consensuais de Solução de Conflitos. Disponível em <http://www.tjrs.jus.br/site/publicacoes/administrativa/>. Acesso em out. de 2018

RIO GRANDE DO SUL. Tribunal de Justiça do Estado do Rio Grande do Sul. Resolução Órgão Especial no 03, de 14 de agosto de 2018. Altera dispositivos da Resolução Órgão Especial no 04/2012 que criou o Núcleo Permanente de Métodos Consensuais de Solução de Conflitos. Disponível em <http://www.tjrs.jus.br/site/publicacoes/administrativa/>. Acesso em out. de 2018

-. Tribunal de Justiça do Estado do Rio Grande do Sul. Conselho Magistratura (Comag). Resolução $\mathrm{n}^{\circ}$ 1.026, 18 de agosto de 2014. Disciplina os Centros Judiciários de Solução de Conflitos e Cidadania (CEJUSC) no âmbito do Tribunal de Justiça do Estado do Rio Grande do Sul. Disponível em <http://www.tjrs.jus.br/site/publicacoes/administrativa/>. Acesso em out. 2018.

- Tribunal de Justiça do Estado do Rio Grande do Sul. Secretaria da Presidência. Ato 041/2015-P. Cria o Centro de Formação e Desenvolvimento de Pessoas da Justiça Estadual. Disponível em <https://www.tjrs.jus.br/site/publicacoes/administrativa/>. Acesso em out. 2018.

-. Tribunal de Justiça do Estado do Rio Grande do Sul. Conselho Magistratura (Comag). Resolução no 1.124, de 26 de fevereiro de 2016. Altera a Res. no 1026/2014-COMAG, que disciplina os Centros Judiciários de Solução de Conflitos e Cidadania (CEJUSC) no âmbito do Tribunal de Justiça do RS. Disponível em <http://www.tjrs.jus.br/site/publicacoes/administrativa/>. Acesso em out de 2018.

-. Tribunal de Justiça do Estado do Rio Grande do Sul. Conselho Magistratura (Comag). Resolução no 1.125, de 14 de março de 2016. Aprova o regulamento da Formação Integral em Justiça Restaurativa e Construção de Paz. Disponível em 
<http://www.tjrs.jus.br/site/publicacoes/administrativa/>. Acesso em out. de 2018.

- Tribunal de Justiça do Estado do Rio Grande do Sul. Conselho Magistratura (Comag). Resolução ㄲo 1.219, de 09 de agosto de 2018. Revogou a Resolução Comag ํo 822/2010 que criou as Centrais de Práticas Restaurativas nos Juizados da Infância e Juventude de Porto Alegre. Disponível em <http://www.tjrs.jus.br/site/publicacoes/administrativa/>. Acesso em out. de 2018.

Corregedoria Tribunal de Justiça do Estado do Rio Grande do Sul. Corregedoria Geral de Justiça (CGJ). Documento-base do Programa Justiça Restaurativa para Século 21. 2014. Disponível em: <http://www.tjrs.jus.br/export /poder_judiciario/tribunal_de_justica/corregedoria_geral _da_justica/projetos/projetos/justica_sec_21/J21_TJRS_cor.pdf>. Acesso em out. 2018.

ZEHR, Howard. Trocando as lentes: um novo foco sobre o crime e a justiça / Howard Zehr; tradução de Tônia Van Acker. ? São Paulo: Palas Athena, 2008. 